\title{
Concomitant Child Strabismus: Clinical Forms and Treatment
}

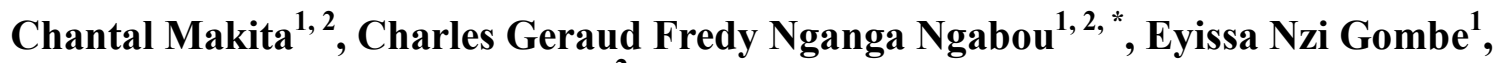 \\ Reinette Messe Ambia Koulimaya ${ }^{2}$
}

${ }^{1}$ Faculty of Health Sciences, University Marien Ngouabi, Brazzaville, Congo

${ }^{2}$ Department of Ophthalmology, University Hospital, Brazzaville, Congo

Email address:

Chantalmakita@gmail.com (C. Makita), fredygeraud@gmail.com (C. G. F. N. Ngabou), geyissa@gmail.com (E. N. Gombé), mchkr_n@yahoo.fr (R. M. A. koulimaya)

${ }^{*}$ Corresponding author

\section{To cite this article:}

Chantal Makita, Charles Geraud Fredy Nganga Ngabou, Eyissa Nzi Gombé, Reinette Messe Ambia koulimaya. Concomitant Child Strabismus: Clinical Forms and Treatment. International Journal of Ophthalmology \& Visual Science. Special Issue: Congenital Eye Abnormalities. Vol. 5, No. 2, 2020, pp. 57-60. doi: 10.11648/j.ijovs.20200502.14

Received: April 15, 2020; Accepted: April 26, 2020; Published: May 27, 2020

\begin{abstract}
Aim: To describe the different clinical forms of concomitant strabismus and the results of treatment. Patients and methods: Descriptive retrospective study conducted from January 2007 to December 2017 (10 years), on records children with strabismic, aged 1 to 16 in the department of Ophthalmology of the University Hospital of Brazzaville. Results: Of the 7,722 children collected during the study period, 130 had strabismus, a rate of $1.7 \%$. Forty three (43\%) children were boys and 74 (57\%) were girls with a sex ratio of 0.75 . The average age of the first consultation was $9.3 \pm 3.2$ years old (1 to 16). The age group of $2-6$ years old was the most represented with $43.9 \%$ of patients. Depending on the type of strabismus we found as many convergent as divergent strabismus which affects both girls and boys. There was $72.3 \%$ monocular strabismus and $27.7 \%$ alternation. Dominance was greater on the right, $30.7 \%$ and $15.4 \%$ dominance on the left. The majority of patients had an initial angle $\geq 25$ prismatic diopters $(\Delta)$, i.e. $43 \%, 38.5 \%$ had a deviation between 10 and $25 \Delta, 18.5 \%$ had a deviation between 10 and $5 \Delta$. Ametropia was associated with strabismus in 107 patients or $82 \%$ of the cases. Optical and orthoptic treatment was prescribed in $67.7 \%$ of cases. 11 patients had deep amblyopia. After treatment $54 \%$ of the patients had a final deviation $\leq 10 \Delta$ and $29.1 \%$ had a final deviation $\geq 25 \Delta$. Conclusion: We found as many convergent strabismus as divergent strabismus. The most representative age group was that of 2 to 6 years old. The treatment was optical and orthoptic.
\end{abstract}

Keywords: Strabismus, Amblyopia, Optical Correction

\section{Introduction}

Strabismus is an ophthalmic syndrome characterized by a deviation of the visual axis of one eye relative to the other. This deviation can be constant or intermittent; It may be constant or intermittent, concomitant or not, with primary or secondary sensory changes. Its frequency is $5 \%$ in Western caucasian [1-2], in African melanoderma this frequency varies from 0.37 to 1.5 [3-5]. The seriousness of the condition stems from the fact that poorly treated, strabismus leads in a significant number of cases to unilateral amblyopia. On the other hand, when the syndrome is recognized and treated in time, this complication can be avoided. The aim of this work is to describe the different clinical forms of concomitant strabismus and the results of treatment.

\section{Patients and Methods}

This is a cross-sectional descriptive study conducted in the department of Ophthalmology the University Hospital of Brazzaville from January 2007 to December 2017, a period of 10 years. We collected the records of patients with concomitant strabismus seen by ophthalmologists and an orthoptist. All children benefited from an oculomotor exam and a cylclopegic objective refraction assessment according to the following protocols: either with atropine $0.3 \%$ or $0.5 \%$ 
for 5, and the refraction was carried out on the 7th day; either cyclopentolate combined with tropicamide, alternating instillation every 5 minutes for 25 minutes. The skiascopy or auto-refractometry was done 20 to 30 minutes after the last drop. Ametropia was only taken into account when it was greater than 0.25 diopters

Visual acuity was assessed on the Pigassou scale in preschoolers (between 2 and 6 years old), in school children (between 7 and 16 years old), we used the Monoyer scale. However, in children under 2 years of age, visual acuity has not been evaluated.

The deviation from strabismus was assessed using Behrens' rule, following the Krimsky method evaluated in prismatic diopter $(\Delta)$.

An examination of the anterior segment and the fundus was also performed.

Three types of treatment were used in our study: first optical treatment alone used in strabismus with refractive error, consisting of a total optical correction; then an orthoptic treatment was associated with optical treatment when the optical component alone was insufficient, consisting of occlusions; finally a surgical treatment which aimed to restore the parallelism of the ocular axes.

The following parameters were taken into account: age, sex, type of strabismus, angle of deviation of strabismus before and after treatment.

The exclusion criteria were: incomplete record, inconcomitant, paralytic strabismus, age at onset less than 1 year and encephalopathy. The results were processed by Excel software for the analysis of the data series.

\section{Results}

We collected 130 strabismic patient records out of the 7,722 children received during the study period, a frequency of $1.7 \%$. Forty three (43\%) children were boys and $74(57 \%)$ were girls with a sex ratio of 0.75 . The average age of the first consultation was $9.3 \pm 3.2$ years old ( 1 to 16 ). Table 1 shows the distribution of patients by age of onset and gender. The age group of 2-6 years old was the most represented with $43.9 \%$ of patients.

Table 1. Distribution of patients by age and gender.

\begin{tabular}{lllllll}
\hline Gender & Male & \multicolumn{3}{c}{ Female } & Total \\
\hline Age (years old) & Number & \% & Number & \% & Number & \% \\
\hline$<2$ & 22 & 16.9 & 12 & 9.2 & 34 & 26.1 \\
$2-6$ & 18 & 13.8 & 39 & 30 & 57 & 43.9 \\
$7-10$ & 14 & 10.8 & 20 & 15.4 & 34 & 26.1 \\
$>10$ & 2 & 1.5 & 3 & 2.3 & 5 & 3.9 \\
\hline
\end{tabular}

We found as many convergent as divergent strabismus that affected both girls and boys. The distribution of strabismus by type and gender is shown in Table 2 .

Strabismus was monocular in $62.3 \%$ of the cases and alternating in $27.7 \%$ of the cases.

The associated ametropias, shown in Table 3, were found in $82 \%$ of the patients. Eighteen percent of patients were emmetropic.
Table 2. Distribution of patients by type of strabismus.

\begin{tabular}{lllllll}
\hline $\begin{array}{l}\text { Type of } \\
\text { strabismus }\end{array}$ & \multicolumn{2}{l}{ Convergent } & \multicolumn{2}{l}{ Divergent } & \multicolumn{2}{l}{ Total } \\
\hline Gender & Number & $\mathbf{\%}$ & Number & $\mathbf{\%}$ & Number & \% \\
\hline Male & 26 & 20 & 30 & 23 & 56 & 43 \\
Female & 37 & 28.4 & 37 & 28.4 & 74 & 57 \\
Total & 63 & 48.4 & 67 & 51.4 & 130 & 100 \\
\hline
\end{tabular}

Table 3. Distribution of ametropia by gender.

\begin{tabular}{llll}
\hline Gender Ametropias & Female (\%) & Male (\%) & Total \\
\hline Hypermetropias & 16 & 33 & 49 \\
Myopias & 9 & 11 & 20 \\
Hyperopic astigmatisms & 10 & 14 & 24 \\
Myopic astigmatisms & 6 & 5 & \\
Mixed astigmatism & 2 & 1 & 107 \\
Total & 43 & 64 & \\
\hline
\end{tabular}

We found 11 patients with deep amblyopia and 34 cases of unquantifiable visual acuity who corresponded to too young patients whose age was less than 2 years.

According to the initial deviation shown in Table 4, the majority of patients had an initial deviation $\geq 25 \Delta$ or $43 \%$ of the cases, $38.5 \%$ a deviation between $10-25 \Delta$ and only $18.5 \%$ had a deviation $\leq 10$.

Table 4. Therapeutic modalities.

\begin{tabular}{lll}
\hline Proposed treatment & Number & Percentage (\%) \\
\hline Optical & 4 & 3.1 \\
Optical + Orthoptic & 88 & 67.7 \\
Orthoptic & 20 & 15.4 \\
Optical + Orthoptic + Surgical & 15 & 11.5 \\
Optical + surgical & 3 & 2.3 \\
Total & 130 & 100 \\
\hline
\end{tabular}

With respect to treatment (Table 4 ), $67.7 \%$ of patients had received optical and orthoptic treatment, $2.3 \%$ had received optical and surgical treatment. The three optical, orthoptic and surgical therapeutic methods were used in 20 patients, ie $15.4 \%$. $14.6 \%$ of patients with a departure angle $<10 \Delta$ and an iso-acuity were not treated.

The treatment produced the following results: 54\% of patients had a final deviation $\leq 10 \Delta$ and $29.1 \%$ had a final deviation $\geq 25 \Delta$ (Table 5).

Table 5. Distribution according to the final deviation.

\begin{tabular}{llll}
\hline & \multicolumn{2}{l}{ Deviation angle } \\
\cline { 2 - 4 } & $\mathbf{1 0 D}$ & $\mathbf{1 0 - 2 5 D}$ & $\mathbf{2 5 D}$ \\
\hline Number & 70 & 22 & 38 \\
Percentage (\%) & $54 \%$ & 16.9 & 29.1 \\
\hline
\end{tabular}

Table 6. Distribution according to the initial deviation.

\begin{tabular}{llll}
\hline & \multicolumn{2}{l}{ Deviation angle } \\
\cline { 2 - 4 } & $\leq \mathbf{1 0 D}$ & $\mathbf{1 0 - 2 5 D}$ & $\geq 25 \mathrm{D}$ \\
\hline Number & 24 & 50 & 56 \\
Percentage (\%) & 18.5 & 38.5 & 43 \\
\hline
\end{tabular}

\section{Discussion}

The frequency of strabismus was $1.7 \%$ in our study. This frequency was slightly higher than that found by Ebana [4] in 
Cameroun which was $1.3 \%$. In Europe, this prevalence is around $5 \%[1,2]$

Strabismus is often considered a common condition by parents as long as it is not accompanied by a significant decrease in visual acuity and since the child does not complain of pain.

Out of 130 patients in the series, $57 \%$ were female with a sex ratio of 0.75 . This predominance is also observed by Yogolelo in the DRC and Faghihi in Iran $[6,7]$. However, some authors have not noted a predominance of sex [4, 8-10]. The predominance of women can be explained by the fact that the deviation of the visual axes causes aesthetic damage and forces parents to worry much more about their daughters.

The concept of the age of the first consultation is of paramount importance because the prognosis depends on it. The average age varies from study to study. It was $9.3 \pm 3.2$ years old in our series, 6 years old in that of Azonobi in Nigeria [11], 13 years old according to Ebana in Cameroon [12]. In Asia and western countries, patients are seen early in the first year of life [13-14].

We found as much convergent as divergent strabismus. There is controversy in the literature, indeed some authors have noted a high frequency of divergent strabismus $[3,5$, 12], others believe rather that convergent strabismus is the most frequent form $[6,15,16]$. Thus esotropia is the most frequent deviation in children because of the accommodation-convergence synergy, a phenomenon which is present in near vision, thus bringing the adductor muscles of the eye into play resulting in convergence.

Strabismus was alternating in $27.7 \%$ of cases. This rate is lower than that found by Hugonnier [17] who noted it in $80 \%$ of cases.

Astigmatism was associated with ametropia in $82 \%$ of patients, with a high frequency of hyperopia (49\%). These results are comparable to those reported by Yogolelo [6] in the DRC where hyperopia was the common form of ametropia (45.7\%). Essential strabismus was also one of the significant causes in our series. For Hugonnier [17] this variation represents $25 \%$ of cases.

Amblyopia was present in 11 of our patients and it is often related to anisometropia. This shows the importance of the early management of ametropia in strabismus [12].

The treatment of strabismus calls for a total optical correction with constant wear for 2-3 months. In our study, the treatments offered were of diverse, but the majority of our patients, $67.7 \%$, received optical and orthoptic treatment. This made it possible to go from a proportion of $18.5 \%$ of patients with a deviation less than $10 \Delta$ to $54 \%$, an increase of $35.5 \%$ in this group. However $29.1 \%$ of the patients kept a deviation greater than $25 \Delta$. Our results correspond to those observed by Lebuisson [18] who states that $30-50 \%$ of strabismus recover all of the monocular and binocular sensory function. Patients undergoing optical, orthoptic and surgical treatment had binocular vision with aesthetic healing. The overall therapeutic result was satisfactory because $54 \%$ of cases had recovered from a physiological deviation $\leq 10 \Delta$. Positive outcomes depend on the earliness of the treatment $[19,20]$ because of the age of discovery of the disease and the start of treatment generally occurring before 2 years old. The older the child gets, the worse the outcome.

\section{Conclusion}

Strabismus was as much convergent as divergent in equal proportions, more representative in the age group of 2 to 6 years old. The most common associated ametropia was hyperopia. The treatment reduced the strabismic angle in $35.5 \%$ of the patients.

\section{References}

[1] Graham PA. Epidemiology of strabismus $\mathrm{Br} \mathrm{J}$ Ophthalmol 1974; 58: 224-31.

[2] Lorenz B. Genetic of isolated and syndromic strabismus: Facts and perceptives strabismus 2002; 10: 147-56.

[3] Auzemery A, Andriamanamihadja R, Boisier P. A survery of the prevalence and causes of eye disorders in primary school children in Antananarivo. Cahier Santé. 1995; 5: 163-6.

[4] Ebana C, Ellong A, Omgbwa E, Ebana S, Dohvoma V, Bella L. caractéristiques du strabisme en milieu Camerounais. Rev SOAO 2013; 1: 38-34.

[5] Kikudi Z, Maertens K, Kayembé L. Strabisme et hétérophorie: situation du Zaïre. J Fr Ophtalmol 1988; 11: 765-8.

[6] Yogolelo Lo Asani B, Masau Nkola A, Buyi Musanzayi S, Cilundika Mulenga $P$ et al. Etude du strabisme chez les enfants de 0 à15 ans suivis à Lumbubashi RDC: analyse des aspects épidémiologiques et cliniques. Pan afr Med J. 2015; 22: 66.

[7] Faghihi M, Ostadimoghaddam H, Yekta A A. Ambliopia and strabismus in Iranian school childreens, Mashhad Am, Ophtalmol. 2002; 23 (4) 47-79.

[8] Zhu H, Yu JJ, Yu RB, Ding H, Bai J, Chen J et al. Association between childhood strabismus and refractive error in Chinese preschool childreen. Plos One. 2015 March; 10 (3): e 0120720 .

[9] Robaei D, Kifley A, Mitchell P. Factors associated with a previous diagnosic of strabismus in population based sample of 12 years old Australian chlidren. AmJOphthalmol. 2006; 142: $1085-8$.

[10] Goldstein H, Henderson M, Goldberg ID, Benitez E, Hauwkins CM. Perinotal factors associatiated with strabismus in negro children. AJPH. 1967; 57: 217-28.

[11] Azonobi IR et al. Prevalence and Pattern of strabimus in Ilorin. West AfrJ Med. 2009; 28 (4) 253-6.

[12] Ebana Mvogo SR, Dohvoma Viola A, Omgbwa Eballé A, Ellong A, Belinga Kyé O, Ebana Mvogo C. Profil des amétropies statiques chez les sujets atteints d'un strabisme concomitant à l'Hôpital Général de Douala. Rev SOAO 2016; 1: 13-19.

[13] Chia A, Roy L, Seenyen L. Cocomitant horizontal strabismus: an asian perspective. Br J Ophtalmol. 2007; 91: 1337-40. 
[14] Quéré MA, Péchereau A, Lavenant F. Epidémiologie actuelle de l'amblyopie strabique en France J Fr Ophtalmol 1985; 8: 487-96.

[15] Regoda y, Sefic-Kasumovic S. Role of hereditary factors in strabismus occurrence. Med Arch. 2012; 66 (6): 418-9.

[16] Kac MJ et al. Fréquency of ocular deviation at the strabismus sector of the hospitaldoes servidor publico Estadual de Sao paulo. Arq Bras Oftalmol. 2007; 70 (6): 939-42.

[17] Hugonnier R, HugonnierS. Strabisme hétérophories et paralysies oculomotrice. Paris, Masson 1981; 334-7.
[18] Lebuisson DA, ARON S. La vision binoculaire et les strabismes du jeune enfant. Ped UNEF 1983; 450-51.

[19] Lang J. Strabisme. Diagnostic, formes cliniques et traitement. Maloine, Paris, 1981 98-105.

[20] Birch EE, Stager DR Sr. Long term motor and sensory outcomes after early surgery for infantile esotropia. J AAPOS, 2006; 10: 409-13. 